\title{
Irreversible dual inhibitory mode: the novel Btk inhibitor PLS- 123 demonstrates promising anti-tumor activity in human B-cell lymphoma
}

\author{
Ning Ding ${ }^{1}$, Xitao $\mathrm{Li}^{2}$, Yunfei Shi ${ }^{3}$, Lingyan Ping ${ }^{1}$, Lina $\mathrm{Wu}^{4}$, Kai Fu ${ }^{5}$, Lixia Feng ${ }^{1}$, \\ Xiaohui Zheng ${ }^{1}$, Yuqin Song ${ }^{1}$, Zhengying Pan ${ }^{2}$ and Jun Zhu ${ }^{1}$ \\ ${ }^{1}$ Key Laboratory of Carcinogenesis and Translational Research (Ministry of Education), Department of Lymphoma, Peking \\ University Cancer Hospital and Institute, Beijing, China \\ ${ }^{2}$ Key Laboratory of Chemical Genomics, School of Chemical Biology and Biotechnology, Peking University Shenzhen Graduate \\ School, Xili, Shenzhen, China \\ ${ }^{3}$ Key Laboratory of Carcinogenesis and Translational Research (Ministry of Education), Department of Pathology, Peking \\ University Cancer Hospital and Institute, Beijing, China \\ ${ }^{4}$ Key Laboratory of Carcinogenesis and Translational Research (Ministry of Education), Central Laboratory, Peking University \\ Cancer Hospital and Institute, Beijing, China \\ ${ }^{5}$ Department of Pathology and Microbiology, University of Nebraska Medical Center, Omaha, NE, USA \\ Correspondence to: Jun Zhu, email: zhu-jun@bjcancer.org
}

Zhengying Pan, email: panzy@pkusz.edu.cn

Yuqin Song, email: songyuqin622@163.com

Keywords: BCR signaling, Btk, irreversible inhibitor, targeted therapy, B-cell lymphoma

Received: December 17,2014 Accepted: March 26, $2015 \quad$ Published: April 14, 2015

This is an open-access article distributed under the terms of the Creative Commons Attribution License, which permits unrestricted use, distribution, and reproduction in any medium, provided the original author and source are credited.

\section{ABSTRACT}

The B-cell receptor (BCR) signaling pathway has gained significant attention as a therapeutic target in B-cell malignancies. Recently, several drugs that target the BCR signaling pathway, especially the Btk inhibitor ibrutinib, have demonstrated notable therapeutic effects in relapsed/refractory patients, which indicates that pharmacological inhibition of BCR pathway holds promise in B-cell lymphoma treatment. Here we present a novel covalent irreversible Btk inhibitor PLS-123 with more potent anti-proliferative activity compared with ibrutinib in multiple cellular and in vivo models through effective apoptosis induction and dual-action inhibitory mode of Btk activation. The phosphorylation of BCR downstream activating AKT/mTOR and MAPK signal pathways was also more significantly reduced after treatment with PLS-123 than ibrutinib. Gene expression profile analysis further suggested that the different selectivity profile of PLS-123 led to significant downregulation of oncogenic gene PTPN11 expression, which might also offer new opportunities beyond what ibrutinib has achieved. In addition, PLS-123 dose-dependently attenuated BCR- and chemokine-mediated lymphoma cell adhesion and migration. Taken together, Btk inhibitor PLS-123 suggested a new direction to pharmacologically modulate Btk function and develop novel therapeutic drug for B-cell lymphoma treatment.

\section{INTRODUCTION}

B-cell lymphoma is characterized by the malignant growth of B-lymphocytes in the lymph system and comprises various subtypes with distinct pathological characteristics, clinical features and prognoses [1]. In China, approximately 5-6 new lymphatic malignancy cases are diagnosed per 100,000 people per year, and B-cell lymphoma accounts for approximately $66 \%$ of these patients. Patient prognosis has been significantly improved by combination immunotherapy and rituximab; however, approximately $1 / 3$ of late-phase patients still develop primary and secondary resistance to the chemotherapy [2]. Therefore, the development of new targeted drugs for the 
treatment of this debilitating disease is urgently needed.

The BCR signaling pathway has gained significant attention owing to its essential role in the pathogenesis of B-cell lymphoid malignancies [3]. BCR signaling transduction is initiated upon stimulation of the BCR complex, which is composed of surface immunoglobulin and two associated proteins: CD79A (Ig $\alpha)$ and CD79B $(\operatorname{Ig} \beta)$. The CD79A and CD79B ITAM domains are phosphorylated by the Src-family kinases upon membrane-bound antigen stimulation, which triggers the phosphorylation and activation of regulatory and adaptor proteins, including Syk, Btk and B-cell linker (BLNK). BCR-mediated phosphorylation of the Tyr551 residue in Btk results in a 10-fold increase in Btk's catalytic activity. Then, this form of Btk undergoes autophosphorylation at Tyr223 to become fully activated. Once fully activated, Btk phosphorylates its substrates phospholipase C- $\gamma 2$ (PLC- $\gamma 2$ ) leading to the induction of downstream pathways, such as NF- $\mathrm{KB}$, extracellular signal-regulated kinase (ERK) and NF-AT, which regulate $\mathrm{B}$ cell proliferation, differentiation, and migration [4]. Recently, several drugs targeting BCR signal, especially the Btk inhibitor ibrutinib (PCI-32765), have clearly demonstrated promising therapeutic effects in relapsed/ refractory chronic lymphocytic leukemia (CLL) and B-cell non-Hodgkin lymphoma (B-NHL) [5-7]. Ibrutinib is the first selective and irreversible small-molecule Btk inhibitor assessed in clinical trials for the treatment of B-cell lymphoma. Ibrutinib interacts with the cysteine residue at position 481 in Btk (Cys481), which is located at the rim of the ATP-binding pocket. In a phase I, open-label trial, ibrutinib demonstrated notable anti-lymphoma activities and a good safety profile in B-cell malignancy patients. The overall response rate (ORR) of evaluable patients was $60 \%$, including a complete response (CR) rate of $16 \%$, which indicates that pharmacological inhibition of BCR pathway holds promise in B-cell lymphoma treatment $[8$, 9].

Investigating the biological function of Btk, de Rooij et al. reported that Btk activation is also regulated via a negative regulation loop that inhibition of Btk catalytic activity increases Tyr551 phosphorylation level $[10,11]$. Thus, one direction for next-generation Btk inhibitors pursued by us was to inhibit both the catalytic activity and the activation of Btk by upstream kinases. By targeting both properties, these new inhibitors might potentially downregulate BCR and other related signal transduction pathways more effectively. Meanwhile, the different selectivity profile of these inhibitors might also offer new opportunities beyond what ibrutinib has achieved. Based on this hypothesis, we recently developed a novel series of covalent irreversible Btk inhibitors based on a Type II scaffold [12]. Two noticeable features of this series of inhibitors have emerged: (1) in contrast to ibrutinib, which only inhibits Btk's catalytic activity, these new inhibitors exhibit a dual-action mode of inhibition for
Btk catalytic activity and its own activation; (2) this series of compounds presents a different selectivity profile from ibrutinib, which demonstrated potent activity against ABL, Blk, Bmx, Btk, EGFR, HER2, HER4, Lck, p38a, Rlk, Tec, and VEGFR $[13,14]$. Among these compounds, PLS-123 displayed impressive potency against $\mathrm{Btk}$ and gave $\mathrm{IC}_{50}$ values of $13 \mathrm{nM}$ against Btk Tyr551 and PLC- $\gamma 2$ Tyr1217 phosphorylation.

In this paper, we demonstrated that this novel Btk inhibitor PLS-123 exhibited more potent anti-proliferative effects than ibrutinib in multiple cellular and in vivo preclinical models of B-cell lineage malignancy, including 14 kinds of cell lines, patients' primary tumor cells and mouse xenograft model. More importantly, the PLS123 's potent efficacy against B-cell lymphoma might be attributed to effective apoptosis induction, dual-action Btk inhibitory mode and alternative selectivity profile offered additional anti-tumor mechanism. Collectively, a new direction was suggested to pharmacologically modulate Btk function and efficiently treat B-cell lymphoma.

\section{RESULTS}

\section{PLS-123 inhibited the viability of B-cell lymphoma cells effectively}

PLS-123 is a novel high selective Btk inhibitor with an $\mathrm{IC}_{50}$ less than $5 \mathrm{nM}$ (Figure $1 \mathrm{~A} \& 1 \mathrm{~B}$ ). The inhibitory activities of PLS-123 on the proliferation of 17 types of B-cell lymphoma cell lines were first analyzed using the cell viability assay. PLS-123 demonstrated enhanced anti-proliferative, dose-dependent effects compared with ibrutinib in 14 of these cell lines without affecting the viability of $\mathrm{CD} 19^{+} \mathrm{B}$ cells from healthy volunteers (Figure 1C). The $\mathrm{GI}_{50}$ values of Btk inhibitors, which were determined from dose-response curves, are presented in Table 1. The DLBCL cell line OCI-Ly7 and FL cell line WSU-NHL displayed the highest PLS-123 sensitivity with $\mathrm{GI}_{50}$ values in the double-digit nanomolar range. By contrast, the $\mathrm{GI}_{50}$ values for ibrutinib were in the micromolar range for these cells. Moreover, PLS-123 also more effectively suppressed the viability of primary tumor cells (Figure 1D). All these findings highlighted a remarkable anti-tumor activity of PLS-123 in vitro.

\section{PLS-123-mediated B-cell lymphoma cytotoxicity is caspase-dependent}

To investigate the mechanisms by which PLS123 induced stronger cytotoxic effects than ibrutinib in malignant B cells, annexin V- and PI-stained apoptotic cells were analyzed by flow cytometry in the PLS-123sensitive OCI-Ly7 cells. The percentage of annexin V-positive and PI-negative apoptotic cells peaked 
A<smiles>C=CC(=O)NCC(=O)Nc1cccc(Nc2ncc(NC(=O)c3cc(NC(=O)c4cccc(C(F)(F)F)c4)ccc3C)cn2)c1</smiles>

B

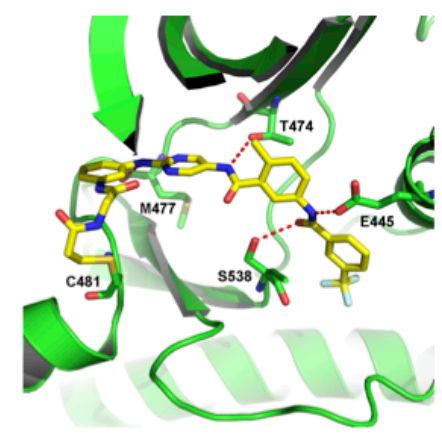

PLS-123
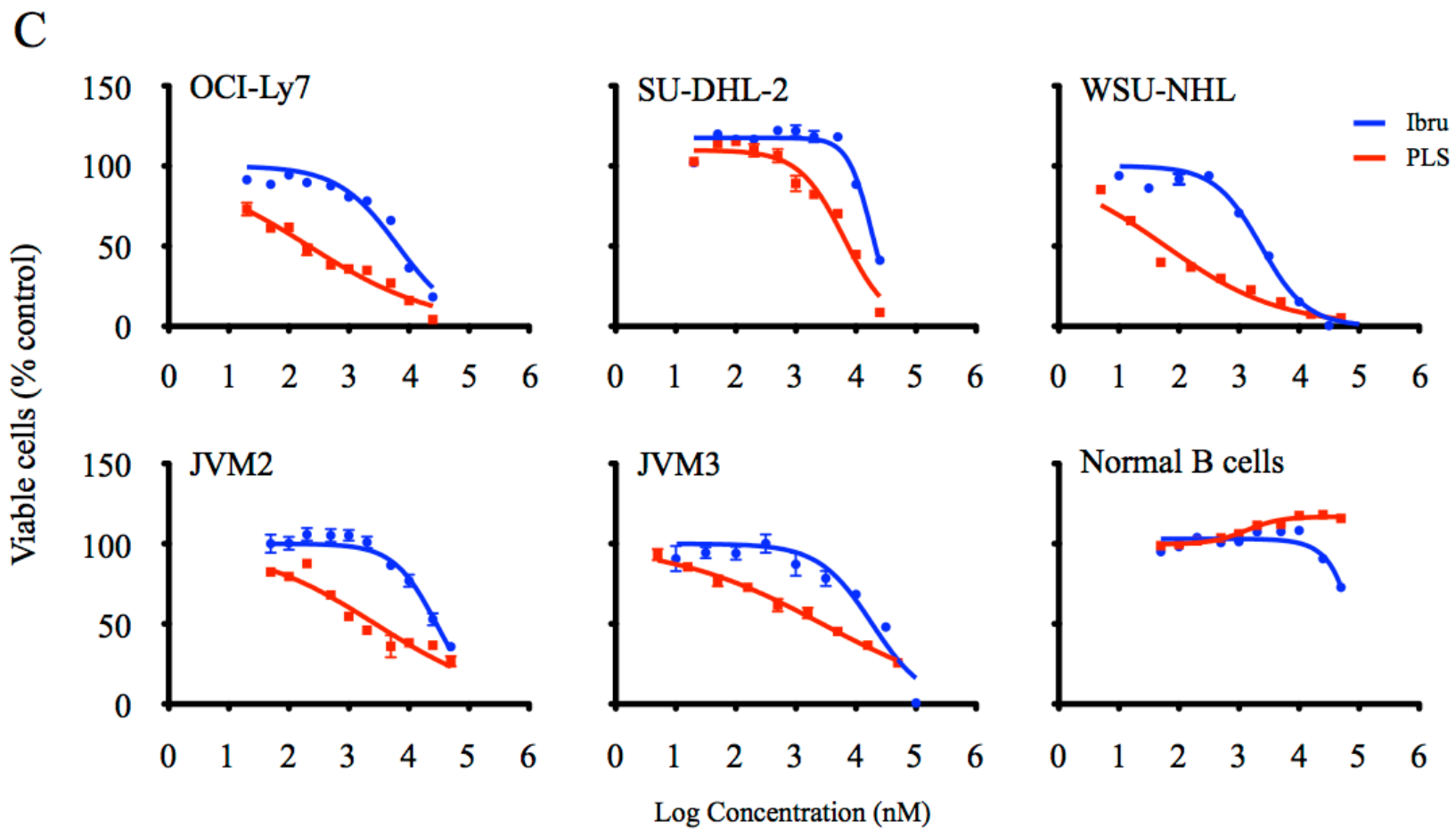

$\mathrm{D}$
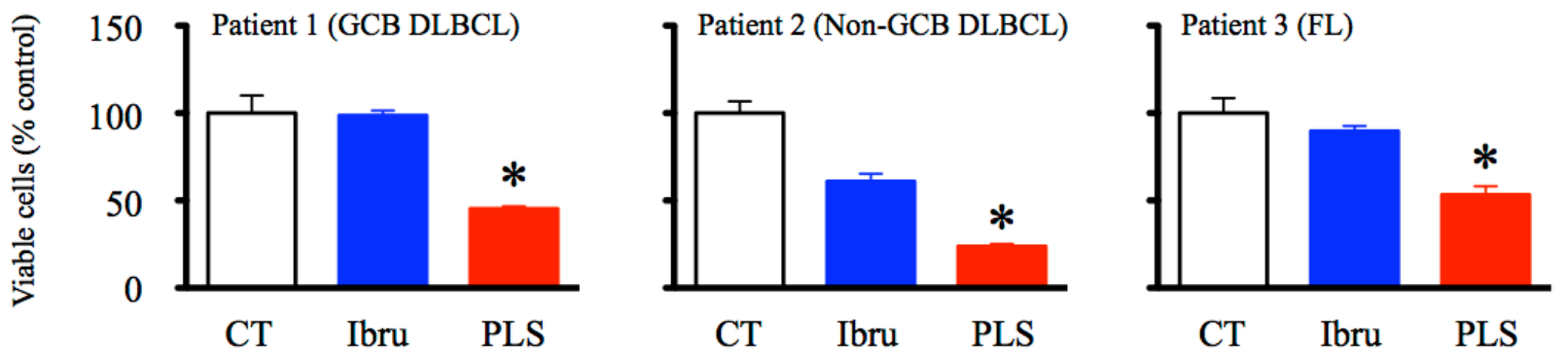

Figure 1: PLS-123 inhibited the viability of B-cell lymphoma cells effectively. A. Chemical structure of novel Btk inhibitor PLS-123. B. Crystal structure of the human Btk in complex with PLS-123. C. B-cell lymphoma cell lines (OCI-Ly7, SU-DHL-2, WSUNHL, JVM2 and JVM3) and CD19+ B cells from healthy volunteers $\left(1 \times 10^{4}\right)$ were treated with the indicated concentrations of ibrutinib, PLS-123 or vehicle for 72 hours. D. Primary tumor cells $\left(1 \times 10^{4}\right)$ from B-cell lymphoma patients were incubated with $1 \mu \mathrm{M}$ ibrutinib, 1 $\mu \mathrm{M}$ PLS- 123 or vehicle for 72 hours. The cell viability was determined using the Cell Titer-Glo luminescent cell viability assay. The results are expressed as the mean of relative activity and S.D. from triplicate cultures. *Significantly decreased compared with ibrutinib treatment $(p<0.05)$. The results are representative of at least three similar experiments. 
Table 1: Cytotoxicity effect of PLS-123 and ibrutinib towards B-cell lymphoma.

\begin{tabular}{|c|c|c|}
\hline Tumor type/cell line & GI $_{50}$, Ibrutinib $(\mu \mathrm{M})$ & GI I $_{50}$, PLS-123 $(\mu \mathrm{M})$ \\
\hline \multicolumn{3}{|l|}{ DLBCL } \\
\hline OCI-Ly7 & 6.60 & 0.22 \\
\hline SU-DHL-2 & 18.38 & 6.35 \\
\hline SU-DHL-6 & 1.83 & 0.06 \\
\hline SU-DHL-16 & 6.31 & 0.81 \\
\hline Pfeiffer & 0.014 & 0.016 \\
\hline OCI-Ly3 & 26.82 & $>50$ \\
\hline \multicolumn{3}{|l|}{ FL } \\
\hline WSU-NHL & 2.32 & 0.06 \\
\hline RL & 6.18 & 1.73 \\
\hline DOHH-2 & 0.52 & 0.02 \\
\hline \multicolumn{3}{|l|}{ CLL } \\
\hline JVM3 & 18.67 & 2.74 \\
\hline \multicolumn{3}{|l|}{ MCL } \\
\hline Mino & 6.62 & 3.94 \\
\hline JVM2 & 28.68 & 2.75 \\
\hline JVM13 & 16.73 & 0.49 \\
\hline Jeko-1 & 20.43 & $>50$ \\
\hline Granta519 & 21.12 & 2.57 \\
\hline Z138 & 19.24 & 15.88 \\
\hline \multicolumn{3}{|l|}{ Burkitt } \\
\hline Namalwa & $>50$ & 26.48 \\
\hline
\end{tabular}

24 hours after PLS-123 treatment (23.5\%), whereas ibrutinib resulted in apoptosis in only $9.9 \%$ of the cells (Figure 2A). These findings correlated with the cell viability results shown in Figure 1. Furthermore, Western blotting analysis suggested that PLS-123 more strongly activated cleaved caspase- $3,-8$ and -9 as well as PARP compared with ibrutinib during apoptosis induction in OCI-Ly7 and SU-DHL-2 cells (Figure 2B). To confirm caspase-3 involvement in this apoptosis process, caspase-3 enzymatic activity was determined after treatment with PLS-123 and ibrutinib for indicated period. As shown in Figure 2C, the active form of caspase-3 was more significantly increased upon treatment with PLS-123 compared with ibrutinib. Meanwhile, PLS-123-induced caspase- 3 cleavage was completely inhibited by the pancaspase inhibitor $\mathrm{z}$-VAD-fmk, thereby demonstrating that PLS-123 induced cytotoxicity against B-cell lymphoma cells is caspase-dependent.

The role of Bcl-2 family proteins in the regulation of caspase activation has been well characterized in the mitochondrial apoptotic pathway. The expressions of Bcl2 family proteins were next analyzed by immunoblotting analysis. As shown in Figure 2D, PLS-123 treatment of malignant $B$ cells resulted in dramatically decreased levels of anti-apoptotic proteins, such as XIAP, Bcl-2, Bcl-xL and Mcl-1. On the other hand, the pro-apoptotic protein BAX was significantly upregulated, thereby suggesting that PLS-123 could promote the apoptotic pathway via regulation of protein targets within mitochondria.
PLS-123 precisely regulates the activation and catalytic properties of Btk, and results in greater attenuation of the BCR activating pathway than ibrutinib

As a novel Btk inhibitor, possible impacts of PLS-123 towards BCR signaling cascades were next investigated by immunoblotting analysis. The upstream BCR signal-activated kinases induce Btk phosphorylation at the Tyr551 residue, thereby resulting in a 10-fold increase in Btk's catalytic activity. This activity is followed by Btk auto-phosphorylation at Tyr223 and activation of downstream substrates. Ibrutinib inhibits the catalytic activities of Btk and the negative BCR pathway feedback loop, resulting in amplified phosphorylation at Tyr551 [11]. In our experiment, after 1 hour pretreatment with both Btk inhibitors, DLBCL cell lines and primary tumor cells were stimulated with anti-IgM to mimic $\mathrm{BCR} /$ antigen encounters and activate the BCR signal pathway. PLS-123 not only more significantly suppressed Btk phosphorylation at Tyr223 compared with ibrutinib but also reduced elevated Btk phosphorylation at Tyr551 (Figure 3A). Upon stimulation with anti-IgM, fully activated Btk coordinates PLC $\gamma 2$ phosphorylation, thereby resulting in the activation of downstream cascades, including the MAPK and AKT/mTOR signaling pathways. Similar to inhibitory activity towards Btk phosphorylation, Western blotting analyses demonstrated that PLS-123 
A

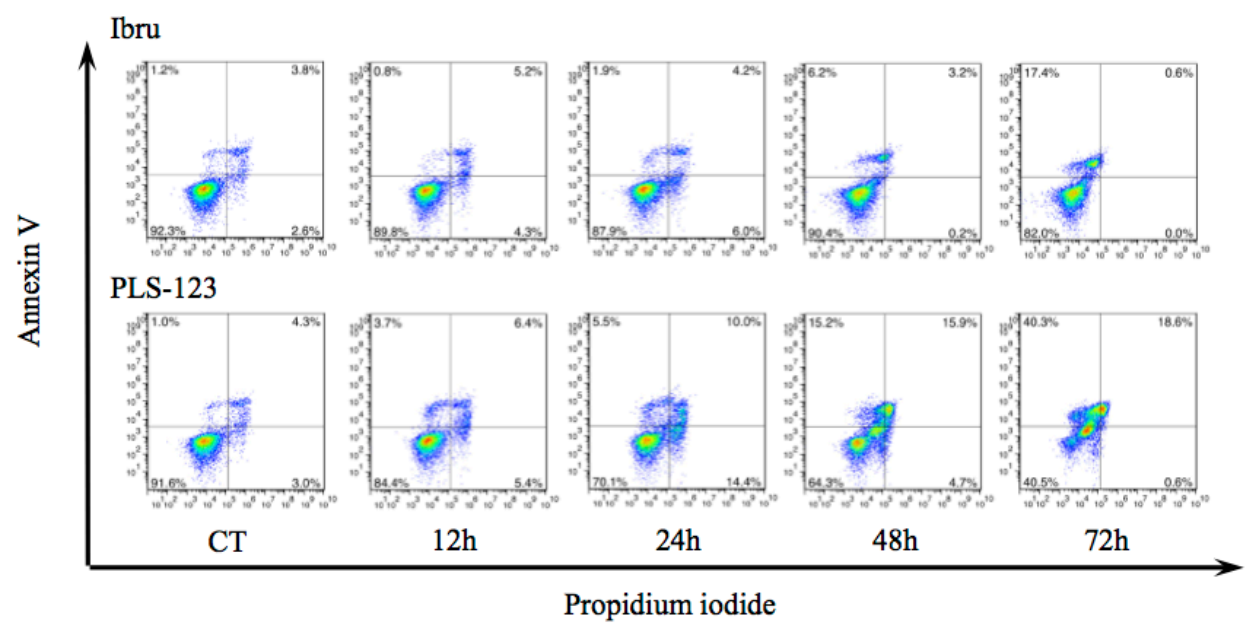

B

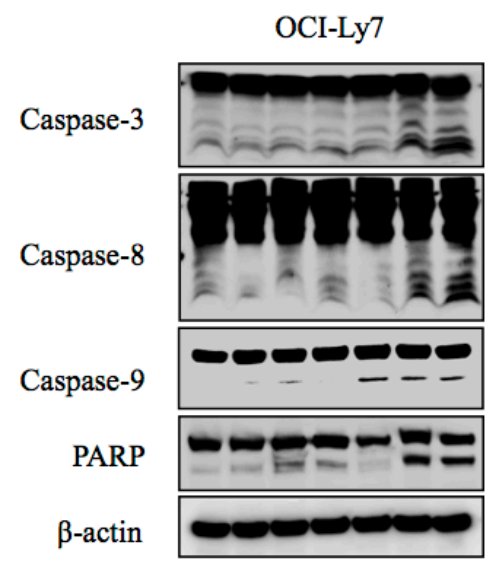

CT $6 \mathrm{~h} 12 \mathrm{~h} 24 \mathrm{~h} 6 \mathrm{~h} 12 \mathrm{~h} 24 \mathrm{~h}$
SU-DHL-2

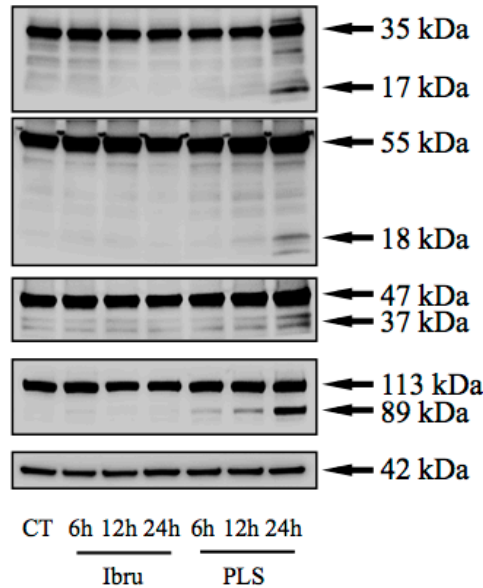

C

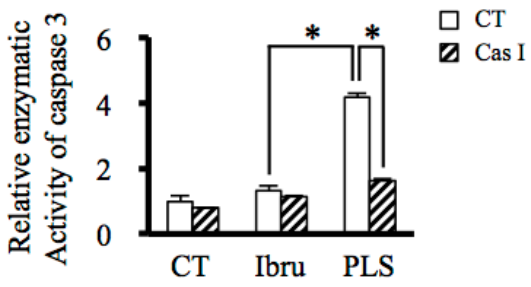

D
OCI-Ly7

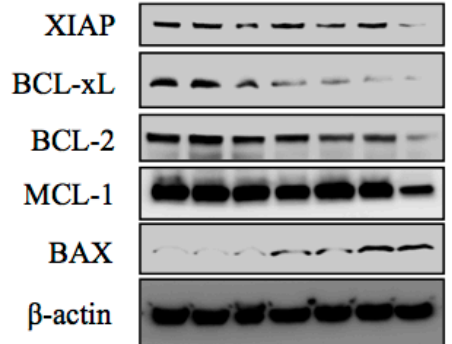

CT 6h $12 \mathrm{~h} 24 \mathrm{~h} 6 \mathrm{~h} 12 \mathrm{~h} 24 \mathrm{~h}$
SU-DHL-2

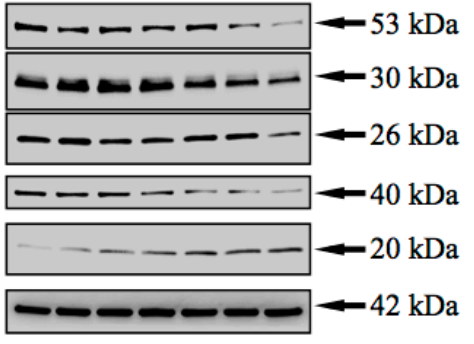

CT $6 \mathrm{~h} 12 \mathrm{~h} 24 \mathrm{~h} 6 \mathrm{~h} 12 \mathrm{~h} 24 \mathrm{~h}$

Figure 2: PLS-123-mediated B-cell lymphoma cytotoxicity is caspase-dependent. A. OCI-Ly7 cells $\left(1 \times 10^{6}\right)$ were cultured with $1 \mu \mathrm{M}$ ibrutinib, $1 \mu \mathrm{M}$ PLS-123 or vehicle for the indicated periods, and apoptotic cells were analyzed by flow cytometry. B \& D. OCILy7 and SU-DHL-2 cells $\left(1 \times 10^{6}\right)$ were treated with $1 \mu \mathrm{M}$ ibrutinib, $1 \mu \mathrm{M}$ PLS-123 or vehicle for the indicated periods. Whole cell extracts were probed by Western blot for Caspase-3, Caspase-8, Caspase-9, PARP, XIAP, BCL-xL, BCL-2, MCL-1 and MAX. $\beta$-actin is shown as a loading control. C. OCI-Ly7 cells $\left(1 \times 10^{6}\right)$ were pre-treated in presence or absence of the pan-caspase inhibitor z-VAD-fmk for 1 hour and then incubated with $1 \mu \mathrm{M}$ ibrutinib, $1 \mu \mathrm{M}$ PLS-123 or vehicle for 24 hours. Caspase- 3 enzymatic activity was measured in tumor cells as described in the Materials and Methods. The results were expressed as the mean of the relative activity and S.D. from triplicate cultures. *Significantly changed compared with the control $(p<0.05)$. Results are representative of at least three similar experiments. 


\section{A}

\begin{tabular}{|c|c|c|c|c|c|}
\hline \multirow{3}{*}{$\begin{array}{l}\text { p-Btk (Tyr551) } \\
\text { p-Btk (Tyr223) }\end{array}$} & OCI-Ly7 & SU-DHL-2 & Patient 1 & \multicolumn{2}{|l|}{ Patient 2} \\
\hline & $--\quad-\infty$ & $-2-\infty$ & ----- & $-\square$ & $77 \mathrm{kDa}$ \\
\hline & - & 一 & $\ldots \ldots$ & $=$ & $77 \mathrm{kDa}$ \\
\hline \multirow{3}{*}{$\begin{array}{r}\text { Btk } \\
\beta \text {-actin }\end{array}$} & 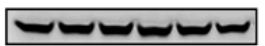 & - $\sim \sim \sim-\sim$ & - & $-\infty=$ & $77 \mathrm{kDa}$ \\
\hline & -1000 & 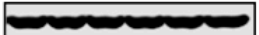 & 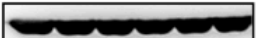 & & $42 \mathrm{kDa}$ \\
\hline & CT Ibru PLS $\frac{\text { CT Ibru PLS }}{\text { Anti-IgM }}$ & CT Ibru PLS $\frac{\text { CT Ibru PLS }}{\text { Anti-IgM }}$ & CT lbru PLS $\frac{\text { CT lbru PLS }}{\text { Anti-IgM }}$ & CT $\quad$ Ibru PLS & \\
\hline \multicolumn{6}{|l|}{ B } \\
\hline p-PLC $\gamma 2$ & $-\quad--$ & - - & $\ldots \ldots$ & $=\Rightarrow$ & $150 \mathrm{kDa}$ \\
\hline PLC $\gamma 2$ & ーーーーーー & ーーーーーー & ーーーーーー & $\longrightarrow-\infty$ & $150 \mathrm{kDa}$ \\
\hline p-Erk1/2 & $=$ & 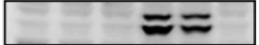 & - & $=$ & $42 / 44 \mathrm{kDa}$ \\
\hline Erk1/2 & $\equiv=\equiv \equiv \equiv$ & 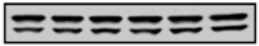 & 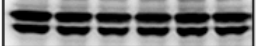 & =25 & $=42 / 44 \mathrm{kDa}$ \\
\hline p-p38 & $--\quad--$ & $-\cdots \cdots$ & $-\cdots-\cdots$ & -- & $-38 \mathrm{kDa}$ \\
\hline p38 & $--\pi--0$ & $--\sigma-\sigma$ & $--\infty-\infty$ & $=$ & $38 \mathrm{kDa}$ \\
\hline p-AKT & - - & $-\cdots \infty-\infty$ & 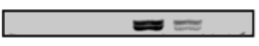 & - & $-60 \mathrm{kDa}$ \\
\hline AKT & $-0-0-0$ & 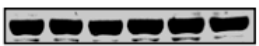 & $=\approx=0$ & 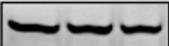 & $-60 \mathrm{kDa}$ \\
\hline p-mTOR & $-\cdots-\cdots$ & $-\cdots \cdots$ & $-\cdots \cdots$ & - & $\leftarrow 289 \mathrm{kDa}$ \\
\hline mTOR & ーーーーーー & ーーーーーー & -ーーーーー & 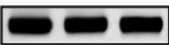 & $-289 \mathrm{kDa}$ \\
\hline$\beta$-actin & run & 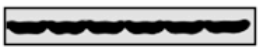 & 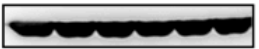 & & $-42 \mathrm{kDa}$ \\
\hline & CT Ibru PLS CT Ibru PLS & CT Ibru PLS CT Ibru PLS & CT Ibru PLS CT Ibru PLS & CT Ibru PLS & \\
\hline & Anti-IgM & Anti-IgM & Anti-IgM & & \\
\hline
\end{tabular}

C
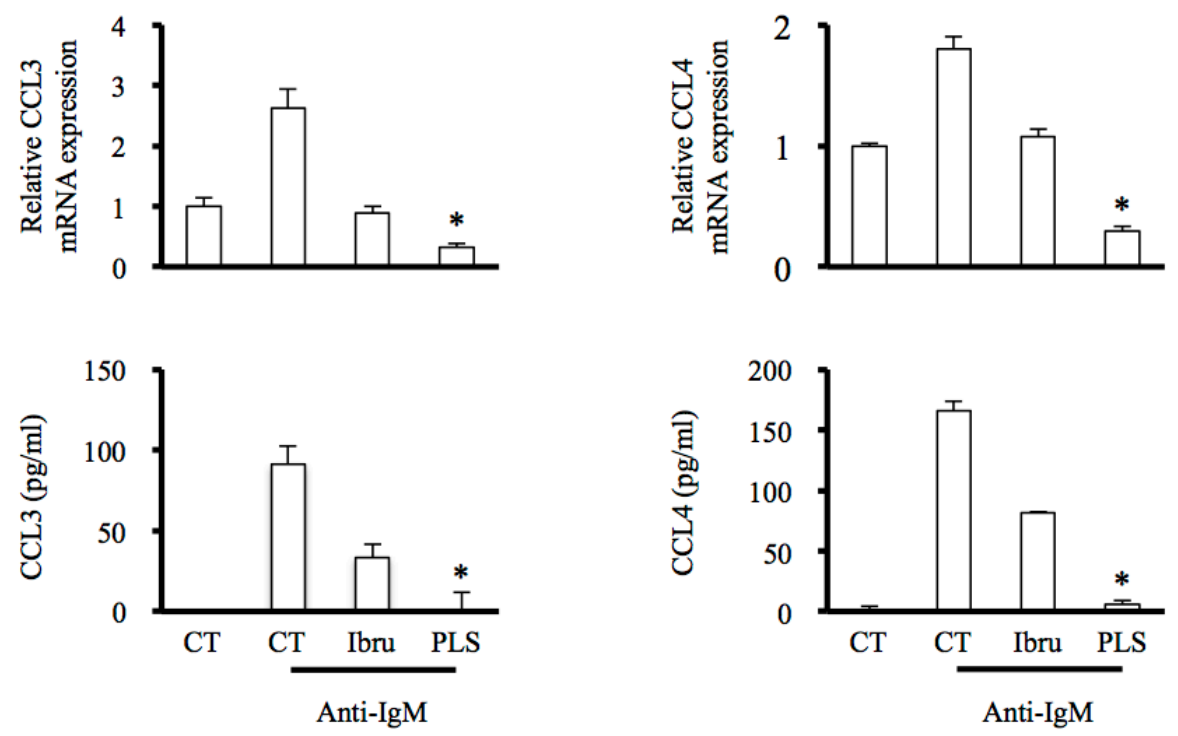

Figure 3: PLS-123 precisely regulates the activation and catalytic properties of Btk, and results in greater attenuation of the BCR activating pathway than ibrutinib. A, B. OCI-Ly7, SU-DHL-2 and primary tumor cells $\left(1 \times 10^{6}\right)$ were pretreated with $1 \mu \mathrm{M}$ ibrutinib, $1 \mu \mathrm{M}$ PLS-123 or vehicle for 1 hour and then stimulated or not with anti-IgM $(5 \mu \mathrm{g} / \mathrm{ml})$ for 10 minutes. Whole cell extracts were probed by Western blot for Btk, PLC $\gamma 2$, ERK, p38, Akt and mTOR. $\beta$-actin is shown as a loading control. C. OCI-ly7 cells $\left(1 \times 10^{6}\right)$ were pretreated with $1 \mu \mathrm{M}$ ibrutinib, $1 \mu \mathrm{M}$ PLS-123 or vehicle for 1 hour and then stimulated by anti-IgM $(5 \mu \mathrm{g} / \mathrm{ml})$ for 12 hours or not. CCL3 and CCL4 mRNA expression and cytokine production were detected by real time PCR and ELISA. *Significantly decreased compared with ibrutinib treatment $(p<0.05)$. The results are representative of at least three similar experiments. 
also effectively reduced PLC $\gamma 2$, ERK1/2, p38, AKT and mTOR activation more than ibrutinib does (Figure 3B).

To further confirm the influence of PLS-123 towards BCR signaling pathway, CCL3 and CCL4 chemokine secretions from tumor cells after Btk inhibitor treatment, which is highly regulated and correlated with the signal activation of the BCR $[15,16]$, were measured via realtime PCR and ELISA. OCI-Ly7 cells were first pretreated with Btk inhibitors for 1 hour before activating the BCR signaling pathway to initiate CCL3 and CCL4 mRNA transcription. As shown in Figure 3C, both chemokines' mRNA and protein expressions were more dramatically reduced by PLS-123 treatment compared with ibrutinib, indicating that PLS-123 resulted in greater attenuation of the BCR activating pathway than ibrutinib. More importantly, all these results might also potentially account for the enhanced anti-proliferative activity of PLS-123 in B-cell lymphoma.

\section{Gene expression profile of B-cell lymphoma post PLS-123 treatment}

Due to the different selectivity profile of PLS-123 from ibrutinib [14], global gene expression profiling was needed to carry out to get a more comprehensive insight into alternative anti-tumor mechanisms of this novel Btk inhibitor. First, compared with vehicle treatment control, Venn diagram illustrated these Btk inhibitors top up- and down-regulated gene changes. Ibrutinib was less efficient with 714 transcripts significantly down $(<$ -1.5 fold, $p<0.05$ ) compared with 1061 for PLS-123. Interestingly, approximately $71 \%$ of transcripts (508 genes) downregulated by ibrutinib were also contained in the PLS-123 group (Figure 4A). Both inhibitors commonly top downregulated representative genes were illustrated by a heatmap in Figure 4B. Consistent with results from immunoblotting analysis in Figure 3, PLS123 could efficiently downregulate $\mathrm{BCR}, \mathrm{AKT} / \mathrm{mTOR}$ and MAPK related signaling pathway.

On the other hand, the different selectivity profile of PLS-123 from ibrutinib might also contribute to distinct gene expression signatures and offer new opportunities beyond what ibrutinib has achieved. Volcano plots of 1441 genes changed in PLS-123 treatment alone (Down: 553 genes; Up: 888 genes) were then used to select additional anti-tumor target of the novel Btk inhibitor. When filter criteria were set for fold change $<-1.5$ and $p<0.001,10$ genes significantly decreased by PLS- 123 were identified in Figure 4C. The mRNA expression analysis of these ten genes using real-time PCR further confirmed that PLS-123 led to significant downregulation of PTPN11 expression that might be due to the different selectivity profile of this inhibitor. As an important oncogenic gene in malignant B cells [17, 18], the inhibition of PTPN11 expression might also contribute to great efficacy of this novel Btk inhibitor. To demonstrate this hypothesis, PTPN11 and Btk knockdown effect on lymphoma cell viability as revealed by siRNA transfection. This co-transfection produced obvious anti-proliferative activity towards tumor cells, suggesting that PLS-123 might suppress tumor growth through combination Btk and PTPN11 inhibition (Figure $4 \mathrm{E})$.

\section{PLS-123 overcomes BCR- and chemokine- mediated lymphoma cell adhesion and migration}

B-NHL patients administered ibrutinib in clinical trials display reduced lymphadenopathy accompanied by substantial lymphocytosis, suggesting that the potential anti-adhesion activity of ibrutinib triggers B-lymphoid malignant cell mobilization from tumor tissues to the peripheral blood. To investigate possible effects of PLS123 in active BCR- and chemokine-mediated adhesion, we analyzed anti-IgM- and chemokine CXCL12-induced adhesion to the extracellular matrix component fibronectin and the cellular adhesion molecule VCAM-1 in Namalwa cells. Compared with ibrutinib's inhibitory effects, our novel Btk inhibitor PLS-123 more significantly attenuated anti-IgM- and CXCL12-mediated adhesion to fibronectin and VCAM-1 in a dose-dependent manner (Figure 5A). Moreover, CXCL12 and its cognate receptor CXCR4 axis also appear to be crucial for migration and homing of malignant B cells via activation of BCR signal pathway [19]. In transwell culture system, PLS-123 also more efficiently blocked neoplastic cells migration toward chemokine CXCL12 through its dual-action inhibitory mode of Btk activation (Figure 5B \& 5C).

\section{PLS-123 induces anti-tumor activities in B-cell lymphoma in vivo}

The in vivo anti-tumor activity of the Btk inhibitors was examined in SCID mice inoculated with OCI-Ly7 cells. When the tumor volume was approximately 100$150 \mathrm{~mm}^{3}$, the mice were intraperitoneally administered the indicated concentrations of the Btk inhibitors. Fifteen days after administration, OCI-Ly7 tumor-bearing animals treated with 5 or $10 \mathrm{mg} / \mathrm{kg}$ of PLS- 123 and $20 \mathrm{mg} / \mathrm{kg}$ ibrutinib resulted in significant effects blocking tumor growth. Similar to previous results from in vitro models, PLS- 123 also demonstrated more anti-growth effects than ibrutinib at the same drug dosage of $10 \mathrm{mg} / \mathrm{kg}(p=0.038)$. Mice treated with $20 \mathrm{mg} / \mathrm{kg}$ of PLS-123 displayed the strongest suppressive activities, and this dosage induced $45 \%$ tumor reduction without significant effects on body weight ( $p=0.418$; Figure 6A \& 6B).

To further evaluating the proliferation, apoptosis and BCR signal status of tumor tissue post administration of Btk inhibitors, Ki-67, TUNEL and p-Btk immunohistochemistry staining was performed 


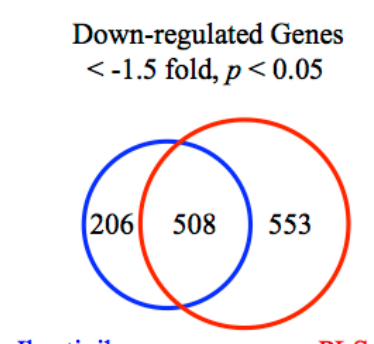

Ibrutinib

PLS-123

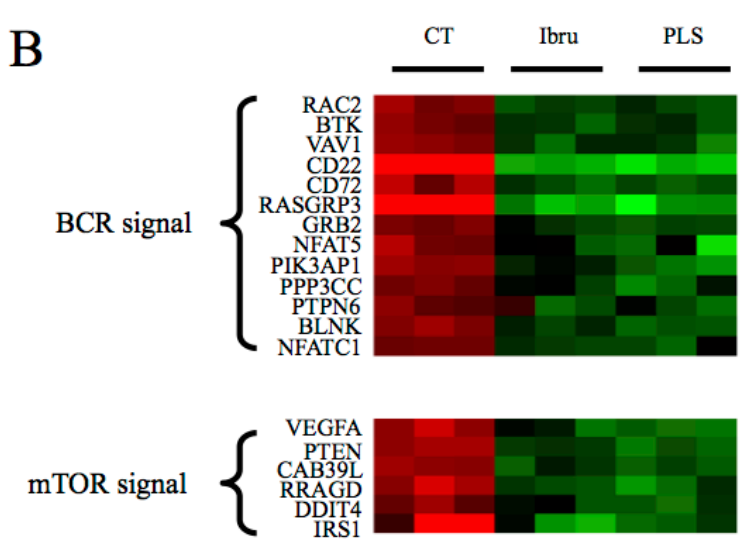

C

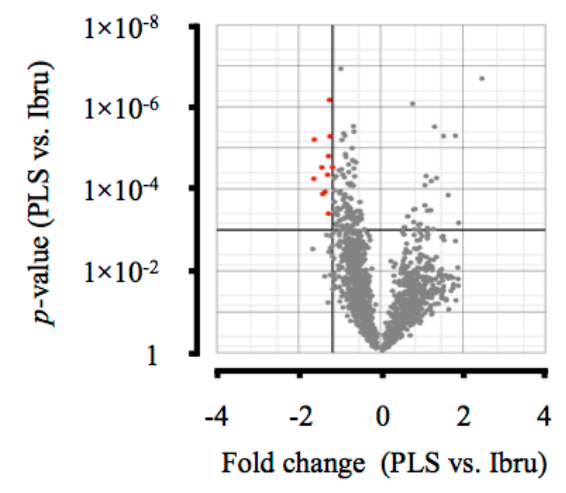

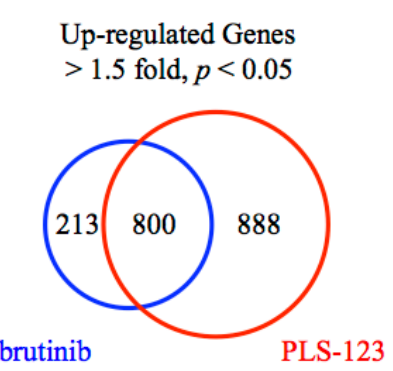

Ibrutinib

PLS-123

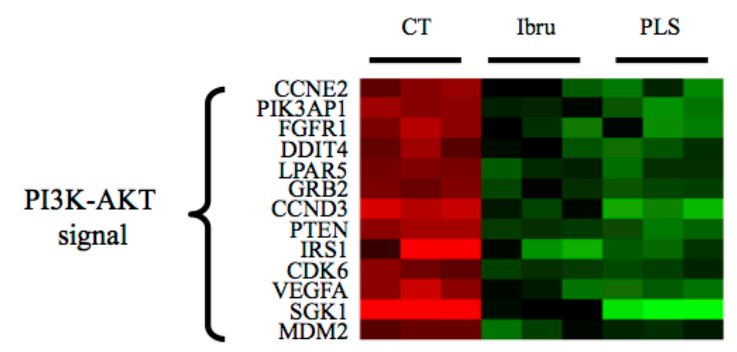

MAPK signal

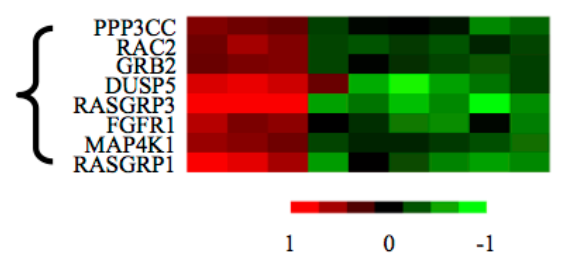

D

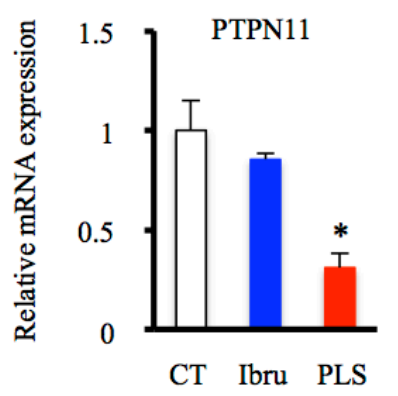

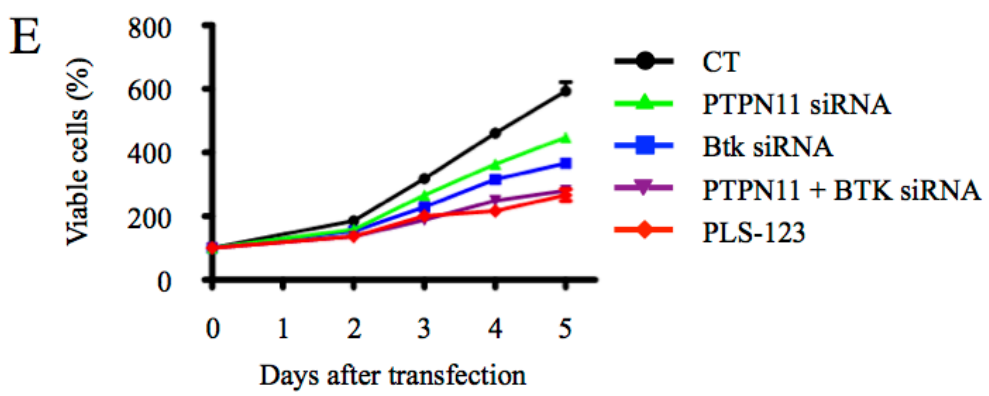

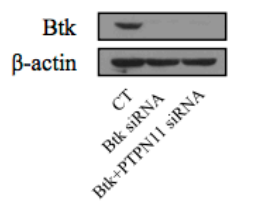

PTPN11

$\beta$-actin

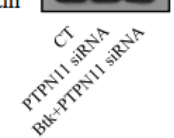

Figure 4: Gene expression profile of B-cell lymphoma post PLS-123 treatment. A. OCI-Ly7 cells exposed for 24 hours with ibrutinib, PLS-123 or vehicle were submitted to gene expression profile analysis. Venn diagram depicting the top up and downregulated gene changes. B. Heatmap of the top representative downregulated genes associated with PLS-123 and ibrutinib treatment. C. The volcano plot depicts a log transformation plot of the fold difference (x-axis) and the $p$ value (y-axis) of indicated genes between PLS-123 and ibrutinib treatment. D. The expressions of PTPN11 gene were further confirmed by real time PCR. E. The OCI-Ly7 cells were transfected with indicated siRNA oligos targeting Btk and PTPN11. The cell viability of tumor cells was determined using the Cell Titer-Glo luminescent cell viability assay. ${ }^{*}$ Significantly decreased compared with ibrutinib treatment $(p<0.05)$. The results are representative of at least two similar experiments. 
A

VCAM-1
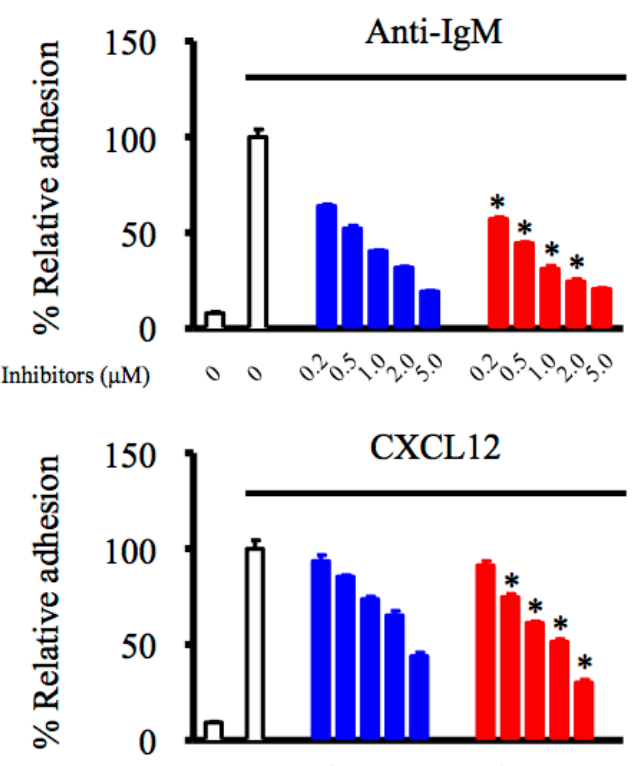

Inhibitors $(\mu \mathrm{M})$

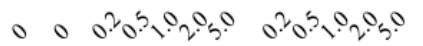

Fibronectin
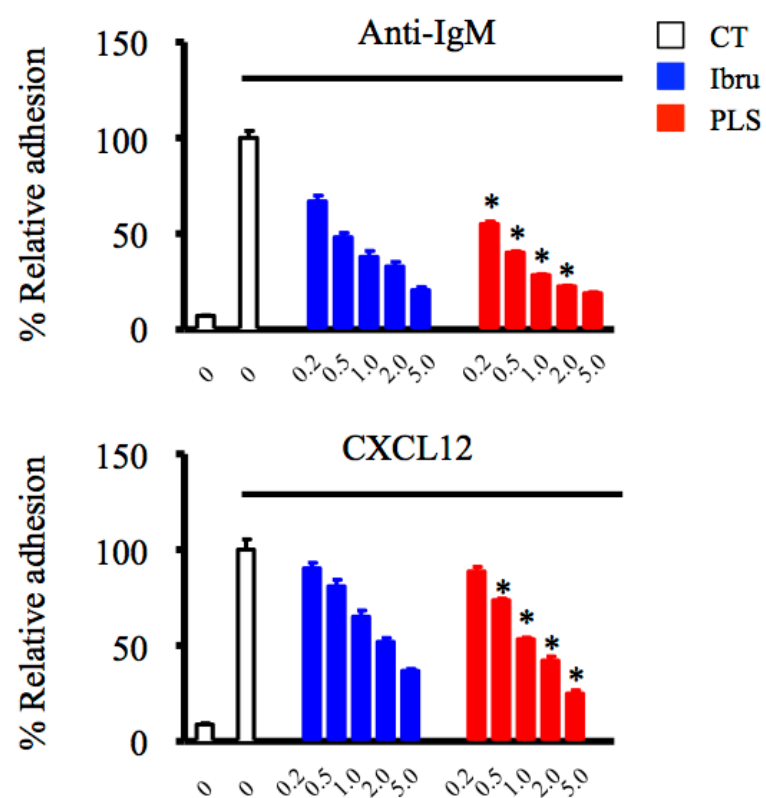

B

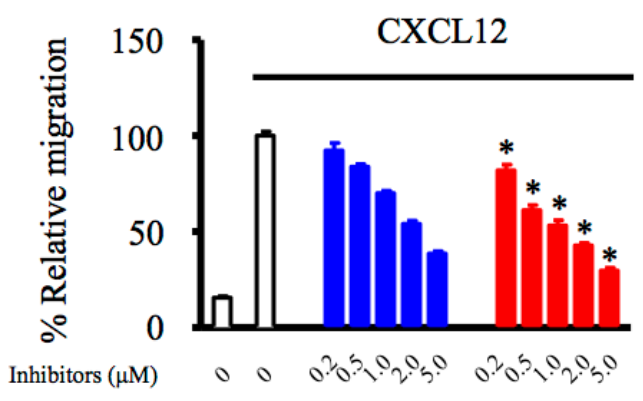

$\mathrm{C}$

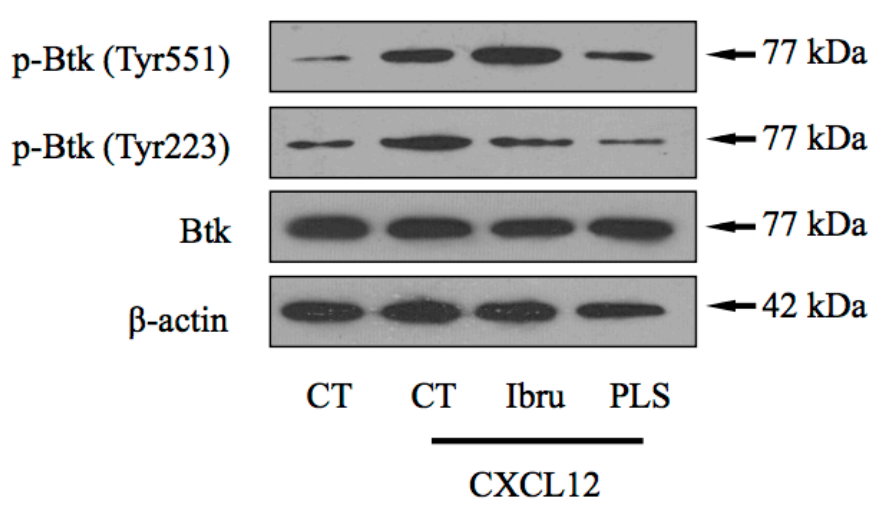

Figure 5: PLS-123 overcomes BCR- and chemokine-mediated lymphoma cell adhesion and migration. A.Namalwa cells pretreated with increasing concentrations of ibrutinib, PLS-123 $(0.2,0.5,1,2$ and $5 \mu \mathrm{M})$ or vehicle were stimulated with anti-IgM or CXCL12 for $30 \mathrm{mins}$, and then tumor cells were subjected to adhesion assays on plates precoated with fibronectin or VCAM-1. B. Namalwa cells were treated with increasing concentration of ibrutinib, PLS-123 $(0.2,0.5,1,2$ and $5 \mu \mathrm{M})$ or vehicle and subjected to a chemotaxis migration assay in transwell plates with filters coated with VCAM-1, and CXCL12 was added into the lower chamber as a chemoattractant. C. Namalwa cells were pretreated with $1 \mu \mathrm{M}$ ibrutinib, $1 \mu \mathrm{M}$ PLS-123 or vehicle for 1 hour and then stimulated or not with CXCL12 for 10 minutes. Whole cell extracts were probed by indicated antibodies for Western blot analysis. *Significantly decreased compared with ibrutinib treatment $(p<0.05)$. The results are representative of at least three similar experiments. 
A

B

$\rightarrow \mathrm{CT}$

$\mathrm{C}$

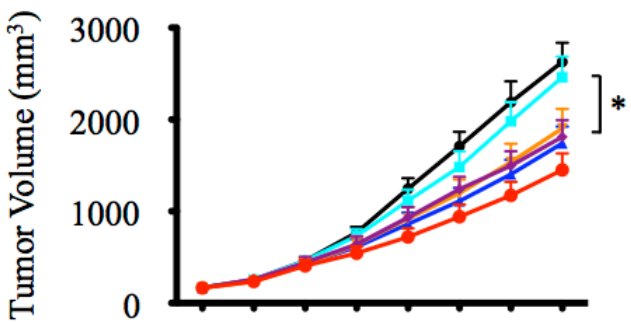

$\begin{array}{llllllll}13 & 15 & 17 & 19 & 21 & 23 & 25 & 27\end{array}$

Days after tumor inoculation $\rightarrow$ PLS $5 \mathrm{mg} / \mathrm{kg} \leadsto$ PLS $10 \mathrm{mg} / \mathrm{kg} \leadsto$ PLS $20 \mathrm{mg} / \mathrm{kg}$

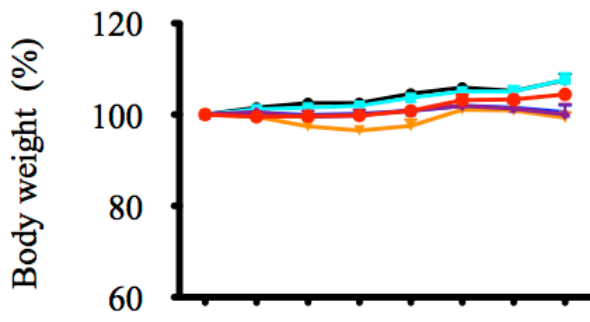

$\begin{array}{llllllll}13 & 15 & 17 & 19 & 21 & 23 & 25 & 27\end{array}$

Days after tumor inoculation
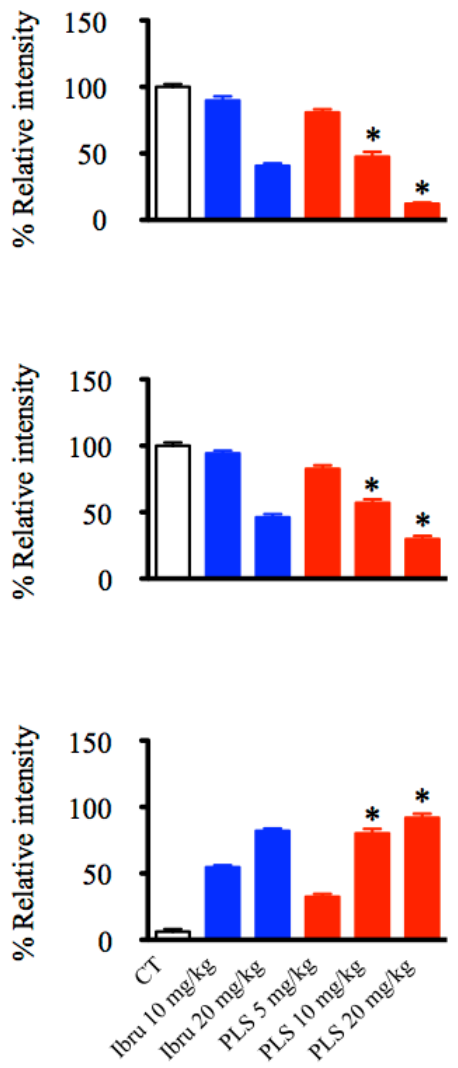

D

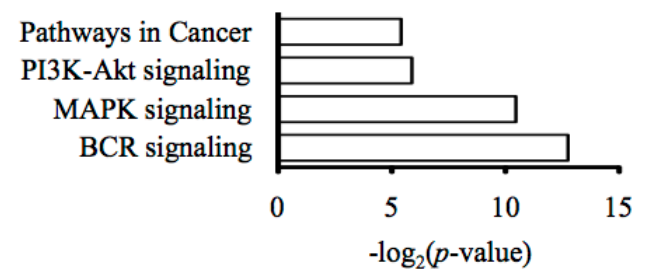

Figure 6: PLS-123 induces anti-tumor activities in B-cell lymphoma in vivo. A\&B. To generate tumors, CB.17/SCID mice were inoculated subcutaneously with $5 \times 10^{6}$ OCI-Ly7 tumor cells in $0.1 \mathrm{ml}$ PBS (each group contains 10 mice). PLS-123 and ibrutinib were administered to the tumor-bearing mice at the indicated concentrations when the tumor volume achieved a diameter of $150 \mathrm{~mm}^{3}$. Body weight and tumor volume of mice was measured every other day during treatment. C. Tumor tissue sections were stained as described under Materials and Methods with indicated antibodies for the determination of Btk inhibitors activity in vivo. *Significantly decreased or increased compared with ibrutinib treatment $(p<0.05)$. D. Total RNA extracted from tumor tissues of PLS-123 $20 \mathrm{mg} / \mathrm{kg}$ and control group ( $\mathrm{n}=6$ at each group) were applied to Affymetrix microarray. The top-ranking significant pathways downregulated by PLS-123 treatment were listed according to the $p$ values $(p<0.05)$. The results are representative of at least two similar experiments. 
on paraffin sections. As shown in Figure 6C, PLS-123 treatment produced a more significant decrease of $\mathrm{Ki}$ 67 and p-Btk expression than the same concentration of ibrutinib achieved. Moreover, activation of apoptosis was also clearly observed post PLS-123 treatment, as indicated by an increase in TUNEL staining. Meanwhile, total RNA extracted from tumor tissues of PLS-123 $20 \mathrm{mg} / \mathrm{kg}$ and control group were applied to gene expression microarray. Pathway analysis of microarray data confirmed that PLS123 mostly down-regulated BCR, MAPK and PI3K-Akt signaling pathway in vivo (Figure 6D). Collectively, all these results confirmed our in vitro findings, in which PLS-123 induced lymphoma cell death via inhibition of BCR signaling and induction of apoptosis.

\section{DISCUSSION}

In this paper, we focused on the anti-tumor activities of the novel Btk inhibitor PLS-123 in B-cell lymphoma. PLS-123's potent anti-proliferative and pro-apoptotic effects in a wide range of B-cell lymphoma subtypes may be attributed to dual-action Btk inhibitory mode and alternative selectivity profile provided additional antitumor mechanisms.

Reports implicated that various B-cell subsets utilize qualitatively distinct BCR signaling to promote their own growth and survival. Lam et al first reported that ablation of BCR expression resulting in a rapid death of peripheral B cells, indicating the requirement for this tonic BCR signaling to sustain the viability of B cells [20]. Tonic BCR signaling was also suggested to sustain the survival of Burkitt lymphoma through engagement of the PI3K pathway [21]. Ibrutinib and our compound PLS-123 are very potent Btk inhibitors, yet exhibit no inhibitory role towards Burkitt lymphoma and normal B cells, suggesting these compounds might not be efficient targeted approaches towards tonic BCR signaling and Btk is not essential for tonic BCR signaling. Some lymphoma subtypes, such as ABC-DLBCL, FL, CLL and MCL, maybe are more akin to rely upon chronic BCR signaling $[3,22]$. Ibrutinib has shown great efficacy in treating MCL and CLL patients yet its anti-proliferative activity is inferior to PLS-123. If these cell lines do rely more on the chronic BCR signaling pathway, PLS-123 could have a better therapeutic effect in the clinic. As already suggested in the results section, the constitutively activated Btk and PLC $\gamma 2$ could be detected not only in non-GCB but also in several GCB-DLBCL (Figure 3A, 3B and data not shown). It is in accordance to literature reports that some GCB-DLBCL relied on activated NF- $\kappa B$, which indicated that chronic active BCR signaling mechanisms might involve in the pathogenesis of these patients [23, 24]. Thus, it is not surprising that the novel Btk inhibitor PLS123 exhibits anti-tumor activity in some GCB-DLBCL.

Btk is a member of Tec family non-receptor protein-tyrosine kinases, which participates in biological events through its catalytic ability and protein-protein interactions. When ibrutinib was used, activated Btk maintained at the Tyr551 phosphorylated stage and did not come back to the resting form, thus it could still engage into the signaling complexes or other functions through protein-protein interactions. Kurosaki et al also reported that phosphorylation of Tyr551, but not Tyr223, is the key regulatory position for BCR signaling activation using Btk-deficient DT40 cell line expressing Btk (Y223F) and Btk (Y551F) mutation models [25]. Thus, in contrast to ibrutinib, which only inhibits Btk's catalytic activity at Tyr223, our novel developed Btk inhibitor PLS-123 abolished Btk's activation via transphosphorylation at Tyr551 and subsequent autophosphorylation at Tyr223, which resulted in a more concise and effective regulation of BCR signal and significant anti-proliferative activities in malignant cells. This dual-action inhibitory mode of PLS-123 could be considered as a simultaneous application of a Btk inhibitor and its upstream kinase inhibitor to doubly control the BCR signal pathway. One advantage of this approach is that it does not need to care about which kinase (Lyn, Syk or both) is the primary Btk activator(s).

Enzymatic activity screen showed that ibrutinib is not a very selective inhibitor, but promising clinical efficacy was observed in relapsed/refractory B-cell lymphoma patients, indicating that pharmacological effects through other pathways in addition to inhibition of Btk may function here. Thus, it was very valuable to present a new series of Btk inhibitors that has a different mode of regulation and a different selectivity profile to this field. The alternative selectivity profile of our novel Btk inhibitor might offer new anti-tumor mechanisms and potent inhibitory activities in a wider range of B-cell lymphoma subtypes. In our experiment, the microarray results demonstrated approximately $71 \%$ of transcripts downregulated post ibrutinib treatment was also similarly attenuated by PLS-123. Moreover, the oncogenic gene PTPN11, which was significantly decreased by PLS-123, was identified as an additional anti-tumor mechanism of this novel Btk inhibitor. It is reported that the hyperactivation and misregulation of PTPN11 played an oncogenic role in various tumor types, especially germinal center derived lymphoma [18, 26, 27]. In our study, the combination Btk and PTPN11 inhibition may synergistically suppress growth of malignant B cells (Figure 4E). This notion indicated that PLS-123's great efficacy and anti-proliferative effects in GCBDLBCL lymphoma might not only be simply attributed to downregulation of BCR signaling pathway alone and alternative selectivity profile provided downregulation of PTPN11 expression should also be considered. However, further experimentation is still needed to explore the precise mechanism.

Caspases are a family of proteases that are frequently activated in mammalian cell apoptosis. Ibrutinib and R406 
inhibited proliferation and induced apoptosis in CLL and DLBCL via caspase activation [28-30]. In our study, we found that PLS-123 efficiently induced the activation of caspases and regulated $\mathrm{Bcl}-2$ family members expression, suggesting that PLS-123 potentially activated the mitochondrial apoptotic pathway in a caspase-dependent manner. Moreover, it is well demonstrated that the BCR signaling pathway can sustain the expression of antiapoptotic proteins through activation of the PI3K/Akt and MEK/ERK pathways [31], supporting the notion that PLS-123 suppressed the expression of these proteins via inhibition of downstream BCR-activating pathways.

The interaction of malignant B cells and surrounding tumor microenvironment is thought to contribute to the survival and progress of B-cell malignancies $[32,33]$. The encouraging clinical efficacy of ibrutinib not only results from direct cytotoxic effects but also its inhibition of the cellular adhesion and migration between tumor cells and the surrounding microenvironment [34-37]. After ibrutinib treatment, most CLL and MCL patients display a transient increase in circulating lymphocytes and a reduction in spleen and lymph node size, indicating the anti-adhesion activity of ibrutinib shifts the malignant cells from the infiltrated tissue to the peripheral blood. In our study, antiIgM and chemokine treatment increased the adhesion of B-NHL cells to cellular substrates, such as fibronectin and VCAM-1; this activity was dramatically inhibited by PLS-123 in a dose-dependent manner (Figure 5A), suggesting the essential impact of novel Btk inhibitor towards crosstalk between malignant cells and the microenvironment.

Collectively, our novel dual-action Btk inhibitor PLS-123 suggested a new direction to pharmacologically modulate Btk function and develop potentially therapeutic drug for the treatment of B-cell lymphoma.

\section{MATERIALS AND METHODS}

\section{Cell lines, patient samples and culture conditions}

The human DLBCL cell lines (OCI-Ly7, SUDHL-16 and OCI-Ly3) and MCL cell lines (JVM2, JVM13, Granta519, Mino, Z138 and Jeko-1) were kindly provided by Dr. Fu (University of Nebraska Medical Center, Omaha, NE, USA). SU-DHL-2, SU-DHL-6, Pfeiffer, RL, DoHH2, WSU-NHL, JVM-3, and Namalwa cells were obtained from ATCC (Manassas, VA) and DSMZ (Braunschweig, Germany). All cells were grown in IMDM or DMEM supplemented with $10 \%$ fetal bovine serum (FBS; Gibco, Life Technology), L-glutamine and penicillin-streptomycin in a humidified atmosphere of $5 \% \mathrm{CO}_{2}$ at $37^{\circ} \mathrm{C}$. The authentication of all cell lines was performed using short tandem repeat DNA fingerprinting analysis (Applied Biosystems, Foster City, CA).
B-cell lymphoma biopsy specimens were collected under a protocol that was approved by the Institutional Review Board of the Peking University Cancer Hospital $\&$ Institute, and informed consent was obtained from all patients. Fresh biopsy specimens were cut into small pieces and gently minced over a wire mesh screen to create a cell suspension. Mononuclear cells were isolated via density gradient centrifugation over Lymphoprep (Axis Shield, Oslo, Norway). CD19 ${ }^{+}$primary tumor cells were purified using negative selection with B-cell Isolation Kit (Miltenyi Biotec, Bergisch-Gladbach, Germany). CD19 cell purity was typically greater than $95 \%$ as determined by FACS analysis (BD FACS Aria II, BD Bioscience, NJ, USA).

\section{Reagents and antibodies}

The Btk inhibitors ibrutinib and PLS-123 were synthesized at the laboratory of Dr. Zhengying Pan at Peking University Shenzhen Graduate School according to a previously published procedure $[14,38]$. Antibodies against Caspase-3 (\#9662), Caspase-8 (\#9746), Caspase-9 (\#9508), XIAP (\#2045), BCL-xL (\#2764), BCL-2 (\#2870), MCL-1 (\#5453), BAX (\#5023), phospho-Tyr223-Btk (\#5082), Btk (\#8547), phospho-Tyr759-PLC 2 (\#3874), phospho-Tyr1217-PLC 2 (\#3871), PLC $\gamma 2$ (\#3872), phospho-p38 (\#9211), p38 (\#8690), phospho-Thr308AKT (\#9275), AKT (\#9272), phospho-Ser2448-mTOR (\#2971), mTOR (\#2972), phospho-ERK1/2 (\#4370) and ERK1/2(\#9102) were obtained from Cell Signaling Technology (Danvers, MA, USA). The anti-PARP, phospho-Tyr551-Btk, $\beta$-actin (A5441), IgM, Ki-67 antibodies were obtained from BD Biosciences, Sigma (St. Louis, MO, USA) and Abcam (Cambridge, MA).

\section{Cell viability assay and apoptosis detection}

Cell viability and apoptosis was measured using the Cell Titer-Glo luminescent cell viability assay system (Promega, Madison, WI, USA), Annexin V/PI apoptosis detection kit (BD Biosciences), Active Caspase-3 Quantikine ELISA kit (R\&D Systems Inc., Minneapolis, MN, USA) and in situ cell death detection kit (Roche, Germany) according to the manufacturer's instructions.

\section{Western blotting}

To prepare whole cell extracts, OCI-Ly7 and SUDHL-2 cells were lysed with RIPA lysis buffer [39]. Equivalent amounts of protein $(10 \mu \mathrm{g})$ were resolved on SDS-PAGE gels, transferred and immobilized on nitrocellulose membranes (Amersham, Buckinghamshire, UK) and probed with the appropriate primary and secondary antibodies. Immunodetection was performed 
using a chemiluminescence detection system (Alpha Innotech, San Leandro, CA, USA).

\section{Real-time quantitative PCR}

OCI-Ly7 cells were treated with Btk inhibitors in the presence or absence of anti-IgM for 12 hours, and total RNA was extracted via RNA TRIzol Extraction (Life Technologies). The primer and probe sequences of the target genes are listed as follow: $\beta$-actin, 5'-CCTGGCACCCAGCACAAT-3', 5'-GCCGATCCACACGGAGTACT-3' and 5'-ATCAAGATCATTGCTCCTCCTGAGCGC-3'; CCL3, 5'-GAGCCCACATTCCGTCACCT-3', 5'-CACTGGCTGCTCGTCTCAAA-3' and 5'-CCACTGCTGCCCTTGCTGTCC-3'; CCL4, 5'-CAGCGCTCTCAGCACCAA-3', 5'-AGCTTCCTCGCAGTGTAAGAAAA-3' and 5'-CTCAGACCCTCCCACCGCCTGC-3'.

\section{ELISA}

CCL3 and CCL4 production from tumor cells was detected using Human CCL3 and CCL4 Quantikine ELISA Kits (R\&D Systems).

\section{Adhesion and migration assay}

Namalwa cells pretreated with the indicated concentrations of Btk inhibitors or vehicle were stimulated with anti-IgM or CXCL12 for 30 mins, and then cells were seeded into 96-well plates that were coated with fibronectin (BD Biosciences) or VCAM-1 (Sigma). Thirty minutes later tumor cells were washed twice with PBS and adherent cells were measured using the Cell TiterGlo luminescent cell viability assay system. Migration assays were performed in triplicate with transwell insert chambers coated with VCAM-1. Namalwa cells treated with Btk inhibitors or not in the upper chamber were allowed to migrate towards lower compartment contained CXCL12 (R\&D Systems) for 4 hours. The migration of control untreated cells in the presence of CXCL12 was normalized to $100 \%$.

\section{Microarray hybridization and gene expression analysis}

Sample processing, microarray hybridization and gene expression analyses were performed using the Affymetrix GeneChip System (Affymetrix, Santa Clara, CA, USA). The biotinylated cRNA was fragmented and hybridized to the GeneChip Human Genome U133 Plus 2.0 microarrays (Affymetrix). Pathway analysis was used to identify the significant pathway of the differential genes according to KEGG database [40-42]. The Raw data have been deposited in the Gene Expression Omnibus Database (GSE65816 and GSE65817).

\section{siRNA transfection}

OCI-Ly7 cells were seeded on 24-well plates in complete media on the day of the transfection. siRNA oligonucleotides targeting PTPN11 (5'-GAAGCACAGUACCGAUUUATT-3'), Btk (5'-GGCAGUAAGAAGGGUUCAATT-3') were synthesized by Invitrogen and transfected to cells using the Lipofectamine $^{\text {TM }}$ RNAiMAX reagent (Life Technologies). The efficiency of siRNA knockdown of target genes was determined by Western blotting.

\section{In vivo studies}

Six- to eight-week-old male CB.17/severe combined immunodeficiency disease (SCID) mice were inoculated subcutaneously with $5 \times 10^{6}$ OCI-Ly7 tumor cells in 0.1 $\mathrm{ml}$ PBS for tumor development. Treatments were initiated when the tumor volume achieved approximately 100-150 $\mathrm{mm}^{3}$. According to the dose of ibrutinib widely used in vivo experiment [35], the mice were administered vehicle or 5,10 or $20 \mathrm{mg} / \mathrm{kg}$ of Btk inhibitors intraperitoneally qd for 15 days. The tumor tissue samples were collected from all the 6 groups at 4 hours after the last dosing. All animal experiments were performed according to the guidelines for the care and use of animals, which were approved by the Peking University Cancer Hospital \& Institute.

\section{Immunohistochemistry and Immunofluorescence analysis}

Immunohistochemistry stains for p-Btk were performed in the department of pathology of Peking University Cancer Hospital using the standard streptavidin-biotin-peroxidase immunostaining procedure. For Ki-67 immunofluorescence analysis, paraffin sections were dewaxed, rinsed, and blocked with 2\% BSA for 20 mins. Then slides were incubated with anti-Ki-67 antibody for 2 hours and followed with fluorescein-conjugated secondary antibodies for another 2 hours. DAPI was used for nuclear counterstaining. Slides were mounted with $90 \%$ glycerol in PBS and visualized with a laser scanning confocal microscopy (TCS-SP2, Leica Microsystems).

\section{Statistical analysis}

All experiments were repeated more than three times and representative results are shown in the figures. Results are expressed as mean $\pm \mathrm{SD}$. Statistical analysis was performed using Student's $t$ test. A confidence level 
of $p<0.05$ was considered significant.

\section{ACKNOWLEDGMENTS}

This work was financially supported by NSFC (No. 81470368 and 81201873), 973 program (2013CB910704 and 2011CB504303), Beijing Natural Science Foundation (No. 7132050), Shenzhen Science and Technology Innovation Committee (JCYJ20140509093817688), National Natural Science Foundation of China (No. 81373270), and "985" Basic Research Fund from Peking University.

\section{CONFLICTS OF INTEREST}

The authors declare no conflict of interest.

\section{REFERENCES}

1. Campo E, Swerdlow SH, Harris NL, Pileri S, Stein H, Jaffe ES. The 2008 WHO classification of lymphoid neoplasms and beyond: evolving concepts and practical applications. Blood. 2011; 117:5019-5032.

2. Sehn LH, Donaldson J, Chhanabhai M, Fitzgerald C, Gill K, Klasa R, MacPherson N, O’Reilly S, Spinelli JJ, Sutherland J, Wilson KS, Gascoyne RD, Connors JM. Introduction of combined CHOP plus rituximab therapy dramatically improved outcome of diffuse large B-cell lymphoma in British Columbia. J Clin Oncol. 2005; 23:5027-5033.

3. Young RM, Staudt LM. Targeting pathological B cell receptor signalling in lymphoid malignancies. Nat Rev Drug Discov. 2013; 12:229-243.

4. Woyach JA, Johnson AJ, Byrd JC. The B-cell receptor signaling pathway as a therapeutic target in CLL. Blood. 2012; 120:1175-1184.

5. Advani RH, Buggy JJ, Sharman JP, Smith SM, Boyd TE, Grant B, Kolibaba KS, Furman RR, Rodriguez S, Chang BY, Sukbuntherng J, Izumi R, Hamdy A, et al. Bruton Tyrosine Kinase Inhibitor Ibrutinib (PCI-32765) Has Significant Activity in Patients With Relapsed/Refractory B-Cell Malignancies. J Clin Oncol. 2013; 31:88-94.

6. Byrd JC, Furman RR, Coutre SE, Flinn IW, Burger JA, Blum KA, Grant B, Sharman JP, Coleman M, Wierda WG, Jones JA, Zhao W, Heerema NA, et al. Targeting BTK with Ibrutinib in Relapsed Chronic Lymphocytic Leukemia. N Engl J Med. 2013; 369:32-42.

7. Wang ML, Rule S, Martin P, Goy A, Auer R, Kahl BS, Jurczak W, Advani RH, Romaguera JE, Williams ME, Barrientos JC, Chmielowska E, Radford J, et al. Targeting BTK with Ibrutinib in Relapsed or Refractory Mantle-Cell Lymphoma. N Engl J Med. 2013; 369:507-516.

8. Akinleye A, Chen Y, Mukhi N, Song Y, Liu D. Ibrutinib and novel BTK inhibitors in clinical development. J Hematol Oncol. 2013; 6:59.
9. Novero A, Ravella PM, Chen Y, Dous G, Liu D. Ibrutinib for B cell malignancies. Exp Hematol Oncol. 2014; 3:4.

10. Kang SW, Wahl MI, Chu J, Kitaura J, Kawakami Y, Kato RM, Tabuchi R, Tarakhovsky A, Kawakami T, Turck CW, Witte ON, Rawlings DJ. PKCbeta modulates antigen receptor signaling via regulation of Btk membrane localization. EMBO J. 2001; 20:5692-5702.

11. de Rooij MF, Kuil A, Geest CR, Eldering E, Chang BY, Buggy JJ, Pals ST, Spaargaren M. The clinically active BTK inhibitor PCI-32765 targets B-cell receptor- and chemokine-controlled adhesion and migration in chronic lymphocytic leukemia. Blood. 2012; 119:2590-2594.

12. Liu Y, Gray NS. Rational design of inhibitors that bind to inactive kinase conformations. Nat Chem Biol. 2006; $2: 358-364$

13. Honigberg LA, Smith AM, Sirisawad M, Verner E, Loury D, Chang B, Li S, Pan Z, Thamm DH, Miller RA, Buggy JJ. The Bruton tyrosine kinase inhibitor PCI-32765 blocks B-cell activation and is efficacious in models of autoimmune disease and B-cell malignancy. Proc Natl Acad Sci U S A. 2010; 107:13075-13080.

14. Li X, Zuo Y, Tang G, Wang Y, Zhou Y, Wang X, Guo T, Xia M, Ding N, Pan Z. Discovery of a Series of 2,5-Diaminopyrimidine Covalent Irreversible Inhibitors of Bruton's Tyrosine Kinase with in Vivo Antitumor Activity. J Med Chem. 2014; 57:5112-5128.

15. Burger JA, Quiroga MP, Hartmann E, Burkle A, Wierda WG, Keating MJ, Rosenwald A. High-level expression of the T-cell chemokines CCL3 and CCL4 by chronic lymphocytic leukemia B cells in nurselike cell cocultures and after BCR stimulation. Blood. 2009; 113:3050-3058.

16. Quiroga MP, Balakrishnan K, Kurtova AV, Sivina M, Keating MJ, Wierda WG, Gandhi V, Burger JA. B-cell antigen receptor signaling enhances chronic lymphocytic leukemia cell migration and survival: specific targeting with a novel spleen tyrosine kinase inhibitor, R406. Blood. 2009; 114:1029-1037.

17. Tartaglia M, Martinelli S, Cazzaniga G, Cordeddu V, Iavarone I, Spinelli M, Palmi C, Carta C, Pession A, Arico M, Masera G, Basso G, Sorcini M, et al. Genetic evidence for lineage-related and differentiation stagerelated contribution of somatic PTPN11 mutations to leukemogenesis in childhood acute leukemia. Blood. 2004; 104:307-313.

18. Jiang X, Guo H, Wu J, He Q, Li Y, Wang M, Pan H, Li W, Wang J, Wang Q, Shen J, Ke Y, Zhou R. Critical role of SHP2 (PTPN11) signaling in germinal center-derived lymphoma. Haematologica. 2014; 99:1834-1845.

19. de Gorter DJ, Beuling EA, Kersseboom R, Middendorp S, van Gils JM, Hendriks RW, Pals ST, Spaargaren M. Bruton's tyrosine kinase and phospholipase Cgamma2 mediate chemokine-controlled B cell migration and homing. Immunity. 2007; 26:93-104.

20. Lam KP, Kuhn R, Rajewsky K. In vivo ablation of surface 
immunoglobulin on mature B cells by inducible gene targeting results in rapid cell death. Cell. 1997; 90:10731083.

21. Schmitz R, Ceribelli M, Pittaluga S, Wright G, Staudt LM. Oncogenic mechanisms in Burkitt lymphoma. Cold Spring Harb Perspect Med. 2014; 4

22. Davis RE, Ngo VN, Lenz G, Tolar P, Young RM, Romesser PB, Kohlhammer H, Lamy L, Zhao H, Yang Y, Xu W, Shaffer AL, Wright G, et al. Chronic active B-cell-receptor signalling in diffuse large B-cell lymphoma. Nature. 2010; 463:88-92.

23. Lenz G, Davis RE, Ngo VN, Lam L, George TC, Wright GW, Dave SS, Zhao H, Xu W, Rosenwald A, Ott G, MullerHermelink HK, Gascoyne RD, et al. Oncogenic CARD11 mutations in human diffuse large B cell lymphoma. Science. 2008; 319:1676-1679.

24. Staudt LM. Oncogenic activation of NF-kappaB. Cold Spring Harb Perspect Biol. 2010; 2:a000109.

25. Kurosaki T, Kurosaki M. Transphosphorylation of Bruton's tyrosine kinase on tyrosine 551 is critical for B cell antigen receptor function. J Biol Chem. 1997; 272:15595-15598.

26. Bentires-Alj M, Paez JG, David FS, Keilhack H, Halmos B, Naoki K, Maris JM, Richardson A, Bardelli A, Sugarbaker DJ, Richards WG, Du J, Girard L, et al. Activating mutations of the noonan syndrome-associated SHP2/ PTPN11 gene in human solid tumors and adult acute myelogenous leukemia. Cancer Res. 2004; 64:8816-8820.

27. Yu B, Liu W, Yu WM, Loh ML, Alter S, Guvench O, Mackerell ADJ, Tang LD, Qu CK. Targeting protein tyrosine phosphatase SHP2 for the treatment of PTPN11associated malignancies. Mol Cancer Ther. 2013; 12:17381748.

28. Chen L, Monti S, Juszczynski P, Daley J, Chen W, Witzig TE, Habermann TM, Kutok JL, Shipp MA. SYK-dependent tonic B-cell receptor signaling is a rational treatment target in diffuse large B-cell lymphoma. Blood. 2008; 111:22302237.

29. Gobessi S, Laurenti L, Longo PG, Carsetti L, Berno V, Sica S, Leone G, Efremov DG. Inhibition of constitutive and BCR-induced Syk activation downregulates Mcl-1 and induces apoptosis in chronic lymphocytic leukemia B cells. Leukemia. 2009; 23:686-697.

30. Herman SE, Gordon AL, Hertlein E, Ramanunni A, Zhang X, Jaglowski S, Flynn J, Jones J, Blum KA, Buggy JJ, Hamdy A, Johnson AJ, Byrd JC. Bruton tyrosine kinase represents a promising therapeutic target for treatment of chronic lymphocytic leukemia and is effectively targeted by PCI-32765. Blood. 2011; 117:6287-6296.

31. Longo PG, Laurenti L, Gobessi S, Sica S, Leone G, Efremov DG. The Akt/Mcl-1 pathway plays a prominent role in mediating antiapoptotic signals downstream of the B-cell receptor in chronic lymphocytic leukemia B cells. Blood. 2008; 111:846-855.

32. Herishanu Y, Perez-Galan P, Liu D, Biancotto A, Pittaluga
S, Vire B, Gibellini F, Njuguna N, Lee E, Stennett L, Raghavachari N, Liu P, McCoy JP, et al. The lymph node microenvironment promotes B-cell receptor signaling, NF-kappaB activation, and tumor proliferation in chronic lymphocytic leukemia. Blood. 2011; 117:563-574.

33. Stevenson FK, Krysov S, Davies AJ, Steele AJ, Packham G. B-cell receptor signaling in chronic lymphocytic leukemia. Blood. 2011; 118:4313-4320.

34. Spaargaren M, Beuling EA, Rurup ML, Meijer HP, Klok MD, Middendorp S, Hendriks RW, Pals ST. The B cell antigen receptor controls integrin activity through Btk and PLCgamma2. J Exp Med. 2003; 198:1539-1550.

35. Ponader S, Chen SS, Buggy JJ, Balakrishnan K, Gandhi V, Wierda WG, Keating MJ, O’Brien S, Chiorazzi N, Burger JA. The Bruton tyrosine kinase inhibitor PCI-32765 thwarts chronic lymphocytic leukemia cell survival and tissue homing in vitro and in vivo. Blood. 2012; 119:1182-1189.

36. Tai YT, Chang BY, Kong SY, Fulciniti M, Yang G, Calle Y, Hu Y, Lin J, Zhao JJ, Cagnetta A, Cea M, Sellitto MA, Zhong MY, et al. Bruton tyrosine kinase inhibition is a novel therapeutic strategy targeting tumor in the bone marrow microenvironment in multiple myeloma. Blood. 2012; 120:1877-1887.

37. Chang BY, Francesco M, De Rooij MF, Magadala P, Steggerda SM, Huang MM, Kuil A, Herman SE, Chang S, Pals ST, Wilson W, Wiestner A, Spaargaren M, et al. Egress of CD19(+)CD5(+) cells into peripheral blood following treatment with the Bruton tyrosine kinase inhibitor ibrutinib in mantle cell lymphoma patients. Blood. 2013; 122:24122424.

38. Pan Z, Scheerens H, Li SJ, Schultz BE, Sprengeler PA, Burrill LC, Mendonca RV, Sweeney MD, Scott KC, Grothaus PG, Jeffery DA, Spoerke JM, Honigberg LA, et al. Discovery of selective irreversible inhibitors for Bruton's tyrosine kinase. ChemMedChem. 2007; 2:58-61.

39. Ding N, Yamashita U, Matsuoka H, Sugiura T, Tsukada J, Noguchi J, Yoshida Y. Apoptosis induction through proteasome inhibitory activity of cucurbitacin D in human T-cell leukemia. Cancer. 2011; 117:2735-2746.

40. Alexa A, Rahnenfuhrer J, Lengauer T. Improved scoring of functional groups from gene expression data by decorrelating GO graph structure. Bioinformatics. 2006; 22:1600-1607.

41. Draghici S, Khatri P, Tarca AL, Amin K, Done A, Voichita C, Georgescu C, Romero R. A systems biology approach for pathway level analysis. Genome Res. 2007; 17:15371545.

42. Yi M, Horton JD, Cohen JC, Hobbs HH, Stephens RM. WholePathwayScope: a comprehensive pathwaybased analysis tool for high-throughput data. BMC Bioinformatics. 2006; 7:30. 